\title{
The Choice of Oral and Maxillofacial Surgery as a Dental Specialty by Graduating Dental Students and Interns: A multi-center Survey
}

Udeabor Samuel Ebele ${ }^{1 *}$, Onwuka Chidozie Ifechi ${ }^{1}$, Muaddi Hasan Ahmed ${ }^{1}$, Hamdi Asma Ahmed ${ }^{1}$, Al Nazeh Abdullah $\mathrm{A}^{2}$, Eroje Alezi Braimoh I

${ }^{1}$ Department of Oral and Maxillofacial Surgery, King Khalid University, Abha, Saudi Arabia

${ }^{2}$ Department of Pediatrics and Orthodontics, King Khalid University, Abha, Saudi Arabia

${ }^{3}$ Department of Periondontics and Community Dental Sciences, King Khalid University, Abha, Saudi Arabia

\begin{tabular}{ll}
\hline DOI:10.36348/SJMPS.2019.v05i09.003 & | Received: $31.08 .2019 \mid$ Accepted: 09.09.2019 | Published: 20.09 .2019
\end{tabular}

*Corresponding author: Samuel Ebele Udeabor

\section{Abstract}

Background: Enrollment into Oral and Maxillofacial Surgery (OMFS) in Saudi Arabia is low generally. Aim: To evaluate the reasons guiding the choice of OMFS as a specialty by final year dental students and interns. Methodology: A questionnaire-based cross-sectional survey among final year students and interns across major Dental Colleges in Saudi Arabia. Respondents were asked to provide information regarding demographics, level of training, interest in specialty training, intended areas of specialization and factors influencing choice of OMFS or not. Results: In total, 210 questionnaires were returned. Out of these, 139 (66\%) were final year students and 71(34\%) interns; $112(53 \%)$ were men and 98 (47\%) were women; and most of them 189 (90\%) were in 21-25 years age range. Overall, 209 (99.5\%) were interested in specialty training. Knowledge of the scope of OMFS ranged from $73 \%-90 \%$ and $50 \%$ were interested in OMFS. Main motivation for interest was "desire to be a surgeon" $(\mathrm{n}=71,34 \%)$. "Preference for other specialties" was the reason for lack of interest in OMFS (41\%) and another 32\% said that "long hours of surgeries and night calls" was their reason. Conclusions: Interest in postgraduate training was very high. The respondents demonstrated a good knowledge of OMFS and interest in the specialty also. Desire to be surgeon was the main motivating factor whereas preference for other specialties and the demands of OMFS in terms of the long hours in OR and night calls were reasons for lack of interest in the specialty.

Keywords: Oral and Maxillofacial Surgery; Dental Students, Interns, Saudi Arabia.

Copyright @ 2019: This is an open-access article distributed under the terms of the Creative Commons Attribution license which permits unrestricted use, distribution, and reproduction in any medium for non-commercial use (NonCommercial, or CC-BY-NC) provided the original author and source are credited.

\section{INTRODUCTION}

Oral and Maxillofacial Surgery (OMFS) is primarily a surgical specialty of Dentistry concerned with the management of diseases of the jaws, mouth, face and neck regions [1]. The scope of practice of an Oral and Maxillofacial Surgeon is not limited to diseases of the "teeth" as is the common belief among many, but is indeed very wide and includes many lifethreatening conditions of the craniomaxillofacial complex [2,3]. These include trauma to the craniomaxillofacial region, cancers of the head and neck, facial clefts, orthognathic surgery, surgical extractions of impacted teeth, diseases of temporomandibular joints, diseases of salivary glands, fascial space infections, pre-prosthetic surgery and osseo-integrated implants among others [1].

Because of the extensive nature of the specialty and its similarity to other specialties of surgery, many countries require dual qualification in medicine and dentistry before undertaking training in OMFS [1, 3]. On the other hand, in countries where dentistry is the only required qualification, a prior exposure to the different aspects of medicine and surgery during the undergraduate and specialty training is compulsory. Saudi Arabia falls into the latter category [3].

It is indeed a common knowledge that many medical professionals and the general public have a very low awareness of OMFS [2]. Surveys conducted among graduating medical students show that they have a very limited exposure to OMFS without even understanding the career pathway [4-6]. This could in part result to low numbers of enrollment into the profession of OMFS in many countries as well as misguided referrals. 
The aim of this multi-center cross-sectional survey was to assess the reasons guiding the choice of OMFS as a specialty by the graduating dental students in Saudi Arabia. An understanding of the reasons for seeking other specialties by these students ahead of OMFS will also be sought.

\section{MATERIAL AND METHODS}

The Scientific Research Committee (SRC) of King Khalid University, College of Dentistry Abha, Saudi Arabia approved this study. Data was collected from final year students and interns across major Dental Colleges in Saudi Arabia who were willing to participate in the study. Lower level dental students and dentists already in specialty training were excluded.

A standard questionnaire that was validated by a statistician was developed based on previous studies in this field and the experience of the researchers. The link to the electronic version of the questionnaire was sent via Whatsapp app and E-mail to the respondents who could not be reached physically.

Respondents were asked to provide information regarding demographics, level of training, interest in specialty training, intended areas of specialization and factors influencing choice of OMFS or not. Descriptive statistical analysis was performed on the generated data using SPSS and categorical variables compared by chi-square test. A p value of less that 0.05 was considered statistically significant.

\section{RESULTS \\ General Characteristics of Respondents}

The distribution of the respondents who completed the questionnaire from different Dental Colleges in the Kingdom is shown in table 1. In total, 210 respondents completed and returned our questionnaires. Out of these, 139 (66\%) were final year students and 71(34\%) interns. Slightly more men $(n=112,53 \%)$ than women completed the questionnaire $(n=98,47 \%)$, and majority of them were in the 21 to 25 years age bracket $(n=189,90 \%)$. All the respondents $(n=209,99.5 \%)$ were interested in specialty training except a female student $(n=1,0.5 \%)$.

\section{Knowledge of the Scope of OMFS}

Total numbers of correct responses were used to calculate the knowledge of the scope of OMFS. The respondents gave a good general understanding of the scope of OMFS with a percentage positive response range of $73 \%$ to $90 \%$. Interns $(76 \%-94 \%)$ have a marginally better knowledge of the scope than the final year students $(72 \%$ - 90\%), although this was not statistically significant (Table 2).

Table-1: Gender Distribution of Respondents by Age groups, Level of Training and Institutions

\begin{tabular}{|c|c|c|c|c|c|c|}
\hline Characteristics & Male & $\%$ & Female & $\%$ & Total & $\%$ \\
\hline \multicolumn{7}{|l|}{ Age groups } \\
\hline $21-25 y r s$ & 98 & 51.85 & 91 & 48.15 & 189 & 90.00 \\
\hline $26-30 \mathrm{yrs}$ & 12 & 63.16 & 7 & 36.84 & 19 & 9.05 \\
\hline$>=31 \mathrm{yrs}$ & 2 & 100.00 & 0 & 0.00 & 2 & 0.95 \\
\hline \multicolumn{7}{|l|}{ Level of training } \\
\hline Final year & 71 & 51.08 & 68 & 48.92 & 139 & 66.19 \\
\hline Interns & 41 & 57.75 & 30 & 42.25 & 71 & 33.81 \\
\hline \multicolumn{7}{|l|}{ Institutions } \\
\hline King Khalid University, Abha & 66 & 57.39 & 49 & 42.61 & 115 & 54.76 \\
\hline King Saud University, Riyadh & 27 & 43.55 & 35 & 56.45 & 62 & 29.52 \\
\hline Jazan University & 11 & 68.75 & 5 & 31.25 & 16 & 7.62 \\
\hline Umm Al-Qura University, Mecca & 0 & 0.00 & 4 & 100.00 & 4 & 1.90 \\
\hline Qassim University & 1 & 100.00 & 0 & 0.00 & 1 & 0.48 \\
\hline Riyadh Elm University & 0 & 0.00 & 3 & 100.00 & 3 & 1.43 \\
\hline Others & 7 & 77.78 & 2 & 22.22 & 9 & 4.29 \\
\hline Total & 112 & 53.33 & 98 & 46.67 & 210 & 100.00 \\
\hline
\end{tabular}

Table-2: Knowledge of the Scope of OMFS (Does the following area of surgery fall within the scope of OMFS?)

\begin{tabular}{|l|c|c|c|c|c|c|c|}
\hline Questions & Final year & Yes \% & Interns & Yes\% & Total & Yes\% & $\boldsymbol{P}$-value \\
\hline Trauma to the craniomaxillofacial region & 122 & 87.77 & 61 & 85.92 & 183 & 87.14 & 0.7040 \\
\hline Tumors of head and neck & 114 & 82.01 & 60 & 84.51 & 174 & 82.86 & 0.6500 \\
\hline Facial clefts & 121 & 87.05 & 67 & 94.37 & 188 & 89.52 & 0.1010 \\
\hline Orthognathic Surgery & 121 & 87.05 & 66 & 92.96 & 187 & 89.05 & 0.1950 \\
\hline Surgical extractions of impacted teeth & 122 & 87.77 & 66 & 92.96 & 188 & 89.52 & 0.2460 \\
\hline Diseases of temporomandibular joints & 103 & 74.10 & 56 & 78.87 & 159 & 75.71 & 0.4450 \\
\hline Diseases of salivary glands & 100 & 71.94 & 54 & 76.06 & 154 & 73.33 & 0.5240 \\
\hline Fascial space infections & 118 & 84.89 & 67 & 94.37 & 185 & 88.10 & $0.0450 *$ \\
\hline Pre-prosthetic surgery & 114 & 82.01 & 65 & 91.55 & 179 & 85.24 & 0.0650 \\
\hline Osseo-intergrated implants & 110 & 79.14 & 57 & 80.28 & 167 & 79.52 & 0.8460 \\
\hline Facial reconstruction & 125 & 89.93 & 62 & 87.32 & 187 & 89.05 & 0.5680 \\
\hline
\end{tabular}




\section{Interest in OMFS and other Specialties}

About $50 \%$ of the final year students were interested in specializing in OMFS and only $20 \%$ of the interns had such interest $(\mathrm{p}=0.0001)$. Among the respondents, slightly more males $(n=45,40 \%)$ than females $(n=38,38 \%)$ were interested in OMFS specialty (Figure 1 A \& B). Considering the other specialties, most of the respondents (32\% each) were interested in specializing in Prosthodontics and Endodontics, whereas only $2 \%$ would love to specialize in Oral pathology (Figure 2 a \& B).

\section{Reasons for Interest or Lack of Interest in OMFS}

Majority of the respondents $(n=86,41 \%)$ stated "preference for other specialty" as the reason for lack of interest in OMFS. This was followed by "long hours of surgeries and night calls" as the second most important reason for lack of interest $(32 \%)$ and more females $(38 \%)$ expressed this concern than their male counterparts (27\%) (Figure 3).

The "Desire to be a Surgeon" was the major reason indicated by those that wished to specialize in OMFS ( $\mathrm{n}=71,34 \%)$, followed by "closeness of OMFS to general medicine and surgery" $(n=56,27 \%)$. Financial benefits was the least motivating factor $(\mathrm{n}=16,8 \%)$ (Table 3 A \& B).

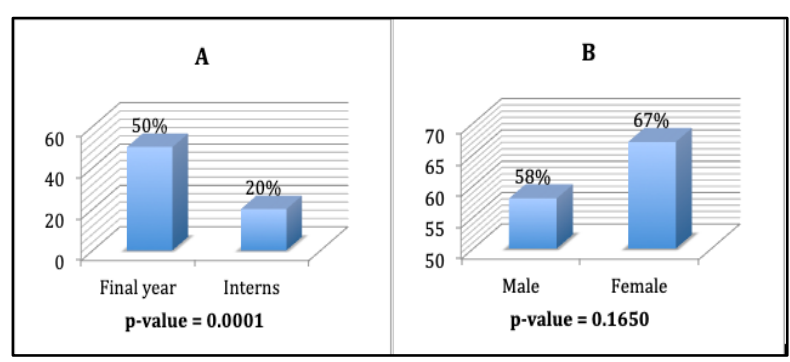

Fig-1: Interest in OMFS Specialty by Level of Training B. By Gender

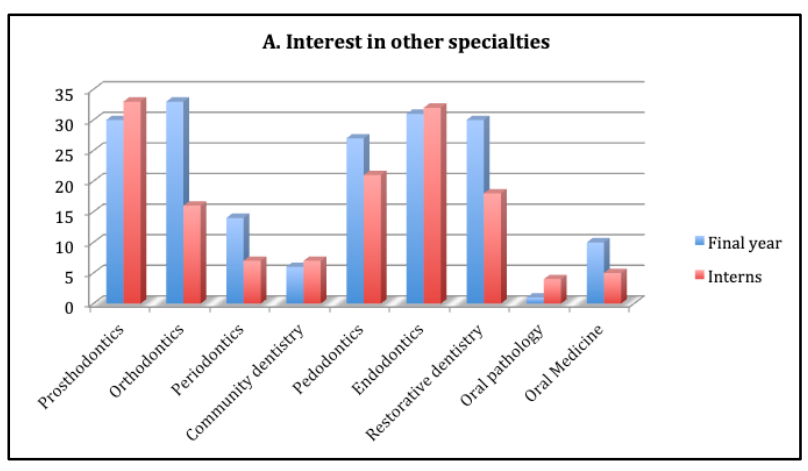

Fig-2 A: Interest in other specialties (By level of training)

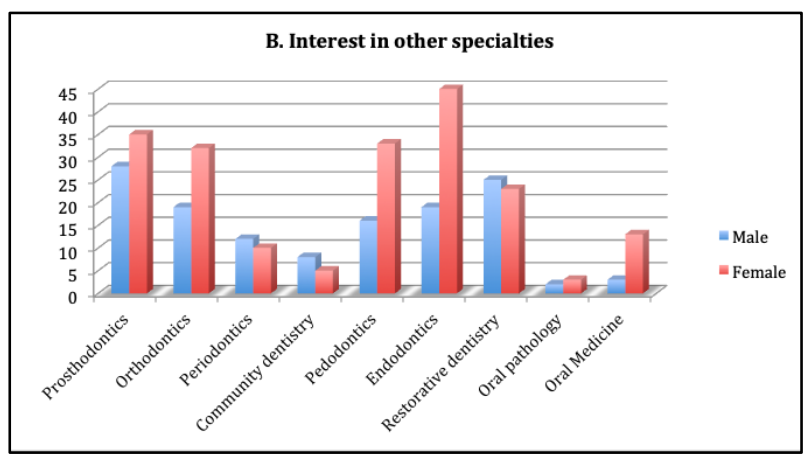

Fig-2 B: Interest in other specialties (By Gender)

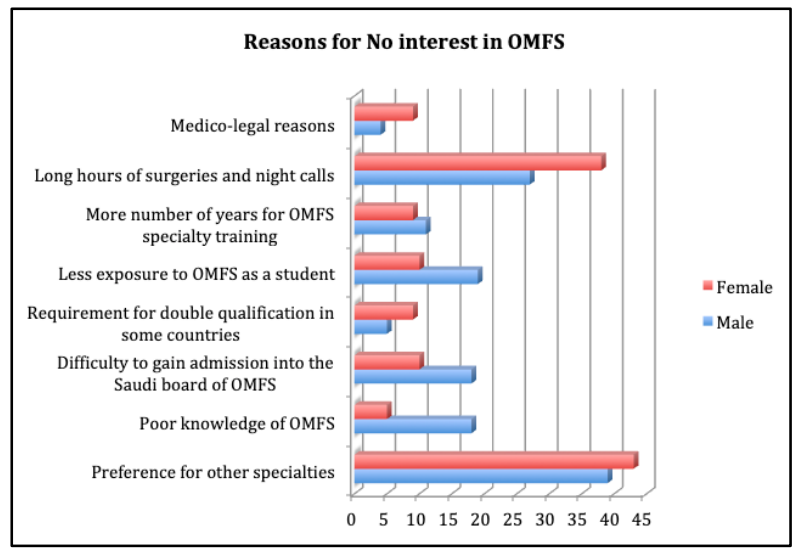

Fig-3: Reasons for lack of interest in OMFS

Table-3: Reasons for interest in OMFS A. By gender

\begin{tabular}{|l|c|c|c|c|c|c|}
\hline & Male & $\%$ & Female & $\%$ & Total & $\%$ \\
\hline Desire to be a surgeon & 37 & 33.04 & 34 & 34.69 & 71 & 33.81 \\
\hline $\begin{array}{l}\text { Closeness of OMFS to general medicine and } \\
\text { surgery }\end{array}$ & 29 & 25.89 & 27 & 27.55 & 56 & 26.67 \\
\hline Financial benefits & 10 & 8.93 & 6 & 6.12 & 16 & 7.62 \\
\hline \multicolumn{2}{|l|}{ Chi-square $=0.6341 P=0.7282$} \\
\hline
\end{tabular}

\begin{tabular}{|l|c|c|c|c|c|c|}
\hline Q. No. 11a & Final year & $\%$ & Interns & $\%$ & Total & $\%$ \\
\hline Desire to be a surgeon & 55 & 39.57 & 16 & 22.54 & 71 & 33.81 \\
\hline $\begin{array}{l}\text { Closeness of OMFS to general medicine and } \\
\text { surgery }\end{array}$ & 40 & 28.78 & 16 & 22.54 & 56 & 26.67 \\
& & & & & & \\
\hline Financial benefits & 11 & 7.91 & 5 & 7.04 & 16 & 7.62 \\
\hline
\end{tabular}




\section{DISCUSSION}

The vast spectrum of work of an Oral and Maxillofacial surgeon notwithstanding, there is an overall low level of awareness of the scope of the specialty by the general public and also among other medical specialties [2, 7, 8]. This low level of awareness directly imparts patients' management due to misguided referrals in most cases. The specialty the world over seems to still be developing and may be the reason for this general low awareness [9]. Saudi Arabia is no exception to this trend as a previous cross sectional survey conducted among 532 dental graduates of King Saud University that embarked on postgraduate dental training, showed that only $10 \%$ specialized in Oral and Maxillofacial Surgery in the long run [10].

It is noteworthy that all the respondents were interested in pursuing specialty training except for a final year female student. She did not give any reason for her response. In our present study, there was a fairly good general understanding of the scope of OMFS by all the respondents with a percentage positive response range of $73 \%$ to $90 \%$. As expected, the interns have a marginally better knowledge of the scope than the final year students, although this was not statistically significant. This very good knowledge of the scope of OMFS can be attributed to the early exposure of dental students in Saudi Arabia to both theoretical and clinical OMFS as from year 3 of their training.

This knowledge obviously translated to interest in the specialty as most of the respondents indicated interest in OMFS more than other specialties. However, this result conflicted with a previous study among Saudi dental students, which gave restorative dentistry and endodontics as the most preferred specialties [11]. The reason for this variation may be the fact that the previous study in question looked at only final year students whereas our study analyzed both final year students and interns. These interns based on more experience and exposures are in a better position to make informed decision having a better knowledge of the requirements and the pathway to specialization in different fields of dentistry.

Prosthodontics and Endodontics from our study are the other two specialties that most of the respondents wished to specialize in. This study however did not focus on the reasons for such decision, as we are mainly interested in their reasons for lack of interest in OMFS. "Preference for other specialties" was the major reason for lack of interest in OMFS by most respondents followed by long hours spent in ORs (operating rooms) and night calls associated with the specialty. More women than men expressed the fear that time was of essence in their choices. This together with family life-demands has remained major deterrents for women who wish to specialize in OMFS [12]. So even with an overall increase in enrollment of women into Dentistry in Saudi Arabia and indeed other parts of the world, the number of women's postgraduate enrollment into OMFS has remained low $[12,13]$.

Other important reasons cited by the respondents for lack of interest in OMFS were "less exposure to OMFS as students" and the "difficulty to gain admission into the Saudi board of OMFS". Most of the Saudi graduates that would love to pursue this specialty abroad, in most cases are discouraged due to the requirement of dual qualifications in Medicine and Dentistry that is the case in most western countries. This therefore narrows the choices for these graduates and leaves a huge number scrambling for the very limited spaces available in the Saudi board of OMFS.

Financial benefit was the least motivating factor for the respondents who wished to specialize in OMFS from the present study. For most of them, it was just the desire to be a surgeon and the closeness of OMFS to general medicine and surgery. There were a few respondents whose motivation was the desire to save lives and yet for others, it was the perceived fact that Saudi Arabia has few OMF surgeons and therefore needs more people in the specialty. All these comments are indeed encouraging and points to the fact that interest in OMFS in Saudi Arabia is on the increase.

\section{CONCLUSION}

Almost all the respondents (final year dental students and interns) were interested in pursuing postgraduate dental training. They also have a very good knowledge of the scope of OMFS and more students than interns indicated interest in the specialty. The reason for lack of interest in the specialty was mainly due to preference for other specialties and the demands of OMFS in terms of the long hours in operating room (OR) and night calls. Desire to be surgeon was the main motivating factor for those that wished to specialize in OMFS.

\section{RECOMMENDATION}

The interest in OMFS is on the increase; therefore more centers for post-graduate training in OMFS across the country should be established to cater for the teeming number of dentists that wish to specialize in the field. New female dental graduates and female students who wish to pursue a career in OMFS should be given the needed encouragement and support to do so by their families and the concerned government agencies.

\section{REFERENCES}


1. Intercollegiate Surgical Curriculum Programme. (2007). The Intercollegiate Surgical Curriculum: Oral and Maxillofacial Surgery Syllabus. ISCP.

2. Vadepally, A., Sinha, R., Uppada, U., BV, R. R., \& Agarwal, A. (2015). Oral and maxillofacial surgery: Perception of its scope among the medical fraternity and general public. Journal of CranioMaxillary Diseases, 4(1), 21-21.

3. Kumar, S. (2017). Training pathways in oral and maxillofacial surgery across the globe - a mini review. Journal of maxillofacial and oral surgery, 16(3), 269-276.

4. Kielty, P. G. C., O’Connor, B. R., Cotter, C. J., Goodson, A. M. C., Payne, K. F. B., \& Tahim, A. (2017). Medical students' understanding of oral and maxillofacial surgery: an Irish perspective. British Journal of Oral and Maxillofacial Surgery, 55(4), 371-377.

5. Goodson, A. M., Payne, K. F., Tahim, A., Cabot, L., \& Fan, K. (2013). Awareness of oral and maxillofacial surgery as a specialty and potential career pathway amongst UK medical undergraduates. The Surgeon, 11(2), 92-95.

6. Mahalingam, S., Kalia, P., \& Mugilan, S. (2015). Oral and maxillofacial surgery in medical schools in the United Kingdom. British Journal of Oral and Maxillofacial Surgery, 53(3), 295-297.

7. Ifeacho, S. N., Malhi, G. K., \& James, G. (2005). Perception by the public and medical profession of oral and maxillofacial surgery-has it changed after 10 years?. British Journal of Oral and Maxillofacial Surgery, 43(4), 289-293.
8. Hunter, M. J., Rubeiz, T., \& Rose, L. (1996). Recognition of the scope of oral and maxillofacial surgery by the public and health care professionals. Journal of oral and maxillofacial surgery, 54(10), 1227-1232.

9. Akinmoladum, V. I., Gbolaham, O. O., Akaditi, O. A., \& Akinyamoju, C. A. (2015). Evaluation of the scope and practice of oral and maxillofacial surgery in Nigeria. Nigerian journal of clinical practice, 18(2), 282-286.

10. Al-Dlaigan, Y. H., Al-Ghamdi, M., Al-Shahrani, A., \& Al-Shahrani, M. (2011). Postgraduate specialties interest, career choices and qualifications earned by male dentists graduated from King Saud University. The Saudi dental journal, 23(2), 81-86.

11. Halawany, H. S., Binassfour, A. S., AlHassan, W. K., Alhejaily, R. A., Al Maflehi, N., Jacob, V., \& Abraham, N. B. (2017). Dental specialty, career preferences and their influencing factors among final year dental students in Saudi Arabia. The Saudi dental journal, 29(1), 15-23.

12. Rostami, F., Ahmed, A. E., Best, A. M., \& Laskin, D. M. (2010). The changing personal and professional characteristics of women in oral and maxillofacial surgery. Journal of Oral and Maxillofacial Surgery, 68(2), 381-385.

13. Risser, M. J., \& Laskin, D. M. (1996). Women in oral and maxillofacial surgery: Factors affecting career choices, attitudes, and practice characteristics. Journal of oral and maxillofacial surgery, 54(6), 753-757. 